\title{
Hepatocellular carcinoma cells surviving doxorubicin treatment exhibit increased migratory potential and resistance to doxorubicin re-treatment in vitro
}

\author{
SEBASTIAN BUSCHAUER ${ }^{1}$, ANDREAS KOCH ${ }^{1}$, PHILIPP WIGGERMANN ${ }^{2}$, \\ MARTINA MÜLLER $^{1}$ and CLAUS HELLERBRAND ${ }^{1,3}$
}

\author{
Departments of ${ }^{1}$ Internal Medicine I and ${ }^{2}$ Radiology, University Hospital Regensburg, D-93042 Regensburg; \\ ${ }^{3}$ Institute of Biochemistry, Friedrich-Alexander University Erlangen-Nuremberg, D-91054 Erlangen, Germany
}

Received July 6, 2016; Accepted December 2, 2016

DOI: $10.3892 / 01.2018 .7887$

\begin{abstract}
Transarterial chemoembolization (TACE) is an established therapeutic approach for the treatment of hepatocellular carcinoma (HCC). Although patients who undergo TACE may have prolonged survival, there are indications that the malignancy of residual HCC tissue can increase subsequent to the procedure. Although hypoxia, which occurs during TACE due to ischemia, is known to contribute to angiogenesis, little is known with regard to the undesirable effects of chemotherapeutic agents on residual HCC cells. Doxorubicin is one of the most commonly used drugs in TACE. The aim of the present study was to analyze alterations in Hep3B and HepG2 human HCC cell lines surviving doxorubicin treatment in vitro. Initially, the toxic concentration range was determined, and doxorubicin was subsequently applied in concentrations that killed $>80 \%$ of the HCC cells. During the first days subsequent to treatment, surviving cells had higher expression levels of the epithelial-mesenchymal transition marker SNAIL, and exhibited increased migratory activity compared with control cells. At 3 weeks after the first doxorubicin treatment, surviving HCC cells tolerated significantly higher doxorubicin concentrations compared with control cells. As a potential explanation for this doxorubicin resistance, significantly increased mRNA expression levels of ATP-binding cassette ABCB1 (multidrug resistance protein 1) and ABCC1 (multidrug resistance-associated protein 1) were observed by reverse transcription-quantitative polymerase chain reaction. In summary, these findings indicate that, following TACE treatment, hypoxia as well as doxorubicin may induce a more
\end{abstract}

Correspondence to: Professor Claus Hellerbrand, Institute of Biochemistry, Friedrich-Alexander University Erlangen-Nuremberg, Fahrstrasse 17, D-91054 Erlangen, Germany

E-mail: claus.hellerbrand@fau.de

Key words: doxorubicin, transarterial chemoembolization, hepatocellular carcinoma, cell migration, chemotherapy resistance malignant phenotype in surviving $\mathrm{HCC}$ cells and decrease susceptibility to further chemotherapeutic treatment.

\section{Introduction}

Hepatocellular carcinoma (HCC) is the fifth most common type of cancer and the third leading cause of cancer-associated mortality worldwide (1), and the incidence continues to increase in numerous countries (2). In the majority of cases, patients have a background of chronic liver disease leading to liver cirrhosis, which is the main risk factor for the development of HCC $(3,4)$. Currently, surgical resection and liver transplantation are the only curative treatment options (5).

Transarterial chemoembolization (TACE) is a minimally invasive treatment that is frequently used to reduce tumor burden in inoperable situations or as bridging therapy prior to transplantation. Although TACE may permit local tumor control and increase survival time in patients with intermediate HCC (Barcelona Clinic Liver Cancer stage B) (6), there is evidence that TACE enhances angiogenesis in $\operatorname{HCC}(6,7)$. While hypoxia, which occurs during TACE due to ischemia, is known to contribute to angiogenesis, little is known about the undesirable effects of chemotherapeutic agents on residual HCC cells subsequent to TACE (8).

The anthracycline doxorubicin is one of the most commonly used drugs in TACE (9). Its main mechanisms of action are intercalation into DNA, inhibition of topoisomerase II and generation of reactive oxygen species (ROS), inducing apoptotic pathways $(10,11)$. While a large proportion of doxorubicin is eliminated from the body unchanged, the main pathway of doxorubicin metabolism is two-electron reduction by cytosolic reductases, of which carbonyl reductase 1 is the most important in the liver (10). However, doxorubicin resistance in HCC cells is predominantly associated with the expression of adenosine triphosphate-binding cassette (ABC) transporters such as $\mathrm{ABCB} 1$ (multi-drug resistance gene; MDR1) or $\mathrm{ABCC} 1$ (multidrug resistance-associated protein 1; MRP1) (10,12-19).

Previous studies concerning the drug resistance of HCC cells have used doxorubicin-resistant cell lines that were generated through constant exposure to rising levels of 
doxorubicin (13,20-22). By contrast, the aim of the present study was to analyze the effects of single-step doxorubicin treatment on surviving HCC cells in vitro, mimicking the situation of HCC cells surviving TACE treatment.

\section{Materials and methods}

Cells and cell culture. HCC HepG2 (cat. no. HB-8065) and Hep3B (cat. no. HB-8064; American Type Culture Collection, Manassas, VA, USA) cell lines were cultured as described previously (23). Briefly, cells were maintained in high-glucose Dulbecco's modified Eagle's medium (DMEM) (Sigma-Aldrich, Taufkirchen, Germany) supplemented with penicillin $(400 \mathrm{U} / \mathrm{ml})$, streptomycin $(50 \mu \mathrm{g} / \mathrm{ml}), \mathrm{L}$-glutamine $(300 \mu \mathrm{g} / \mathrm{ml})$ and $10 \%$ fetal calf serum (FCS; Sigma-Aldrich; Merck Millipore, Deisenhofen, Germany) and were passaged at a 1:5 ratio every 3 days. To select cells that survive treatment with a defined doxorubicin dose $(1 \mu \mathrm{M}), \mathrm{HepG} 2$ and Hep3B cells were incubated with doxorubicin for $48 \mathrm{~h}$. Subsequently, medium was removed, the cell culture dishes were carefully washed with PBS to remove dead cells, and surviving HCC cells $\left(\right.$ HCC $\left.^{\text {surv }}\right)$ were further cultured in normal, doxorubicin-free medium. Control cells $\left(\mathrm{HCC}^{\mathrm{ctr}}\right)$ were continuously cultured in normal medium without doxorubicin. Subsequently, $\mathrm{HCC}^{\text {surv }}$ and $\mathrm{HCC}^{\mathrm{ctr}}$ cells were cultured in parallel and were split when they became confluent. In the two $\mathrm{HCC}^{\text {surv }}$ cell lines this occurred after 1 week. Subsequent to splitting, HCC $^{\text {surv }}$ cells were further cultured and regularly passaged in parallel with $\mathrm{HCC}^{\mathrm{ctr}}$ cells for another 2 weeks.

Microscope images were captured using an Olympus ${ }^{\mathrm{TM}}$ CKX41 microscope (Olympus Corporation, Tokyo Japan) with the ALTRA 20 Soft Imaging System ${ }^{\mathrm{TM}}$ and Cell ${ }^{\mathrm{A}}$ software version 2.6 (Olympus Soft Imaging Solutions GmbH, Münster, Germany). Images were processed using IrfanView ${ }^{\mathrm{TM}}$ software version 4.36 (Irfan Skiljan, Jajce, Bosnia).

Analysis of cell viability and proliferation. Cells were seeded in 6-well plates (200,000/well) or 96-well plates (30,000/well), respectively. After $24 \mathrm{~h}$, analysis of lactate dehydrogenase (LDH) secretion into the supernatant (Cytotoxicity Detection Kit PLUS; Roche Diagnostics GmbH, Mannheim, Germany) and a colorimetric XTT assay (Roche Diagnostics GmbH) were used to analyze the viability of HCC cells subsequent to treatment with doxorubicin as described (24). Cell proliferation was assessed using the xCELLigence impedance measurement system (Roche Diagnostics $\mathrm{GmbH}$ ) according to the manufacturer's protocol.

Analysis of cell migration. The migratory activity of HCC cells was quantified using Cultrex 96-Well Cell Migration assay (Trevigen, Gaithersburg, MD, USA) as described (25). Briefly, HCC cells were seeded into the upper compartment of the provided 96-well micropore plate (10,000 cells/well) in DMEM. The lower compartment was filled with DMEM to study spontaneous cell migration. Subsequent to incubation at $37^{\circ} \mathrm{C}$ for $5 \mathrm{~h}$, cell migration was quantified by fluorometry with an EMax Microplate Reader (MWG Biotech, Ebersberg, Germany).

Analysis of mRNA expression. Total cellular RNA was isolated from doxorubicin-treated and control HepG2 and Hep3B cells using the RNeasy Kit (Qiagen GmbH, Hilden, Germany) according to the manufacturer's instructions. Reverse transcription was performed as described previously (24). Quantitative polymerase chain reaction was performed using a LightCycler Real-Time PCR System (Roche Diagnostics) (24). In each well, $2 \mu \mathrm{l}$ of cDNA template was added to $8 \mu 1$ master mix containing primers and SYBR Green (Bioline $\mathrm{GmbH}$, Luckenwalde, Germany). Melting, annealing and amplification were performed at $95^{\circ} \mathrm{C}(5 \mathrm{sec}), 58^{\circ} \mathrm{C}(10 \mathrm{sec})$ and $72^{\circ} \mathrm{C}$ $(8 \mathrm{sec})$, respectively and repeated for 45 cycles. ABCB1, ABCC1 and SNAIL mRNA expression were analyzed using QuantiTect Primer assays according to the manufacturer's protocol (Qiagen $\mathrm{GmbH}$, Hilden, Germany). Amplification of cDNA derived from 18S rRNA was used for normalization (24), with the following primer sequences: Forward, 5'-AAACGGCTACCACATCCAAG-3', and reverse, 5'-CCT CCAATGGATCCTCGTTA-3'. Results were evaluated using the $2^{-\Delta \Delta C q}$ method (26). Analyses were performed in triplicates and experiments were repeated three times.

Statistical analysis. Values are presented as the mean \pm standard error of the mean. Comparison between groups was made using the unpaired Student's $t$-test or two-way analysis of variance. $\mathrm{P}<0.05$ was considered to indicate a statistically significant difference. All calculations were performed using the statistical computer package GraphPad Prism version 6.01 for Windows (GraphPad Software, Inc., La Jolla, CA, USA).

\section{Results}

Selection of HCC cells surviving doxorubicin treatment. The present study analyzed the effective dose range of doxorubicin on the HepG2 and Hep3B human HCC cell lines. Analysis of LDH release into the supernatant (Fig. 1A) and XTT activity (Fig. 1B) showed that doxorubicin dose-dependently reduced the viability of HCC cells during the $48 \mathrm{~h}$ incubation time. Starting at a dose of $1 \mu \mathrm{M}$ in HepG2 cells and $0.5 \mu \mathrm{M}$ in Hep3B cells, doxorubicin caused a significant increase of LDH levels in the supernatant (2.9-fold, $\mathrm{P}=0.0001$ in HepG2; 1.8 -fold, $\mathrm{P}=0.004$ in Hep3B). XTT activity was significantly reduced by incubation with $0.125 \mu \mathrm{M}$ doxorubicin in HepG2 cells $(60 \% ; \mathrm{P}=0.0075)$ and Hep3B cells $(83 \%$-fold; $\mathrm{P}=0.0003)$. The determined toxic dose ranges were comparable to previous in vitro studies using the same HCC cell lines (27-32). Phase-contrast microscopy confirmed that, after $48 \mathrm{~h}$ incubation with a concentration of $1 \mu \mathrm{M}$ doxorubicin, 10-20\% of HCC cells survived (Fig. 1C). For the next in vitro model that was designed to mimic the circumstances of TACE, doxorubicin was used at a concentration of $1 \mu \mathrm{M}$, which was in the range of doxorubicin concentrations found in human HCC explants following the administration of TACE $(33,34)$. $\mathrm{HCC}$ cells surviving incubation with this doxorubicin dose for $48 \mathrm{~h}\left(\mathrm{HCC}^{\text {surv }}\right)$ and control cells $\left(\mathrm{HCC}^{\text {ctr }}\right)$ were generated as aforementioned.

Analysis of surviving HCC cells in the early phase following doxorubicin treatment. Monitoring of cell growth and morphology with phase-contrast microscopy revealed that $\mathrm{HCC}^{\text {surv }}$ cells developed a spindle-like, outstretched, 
A a

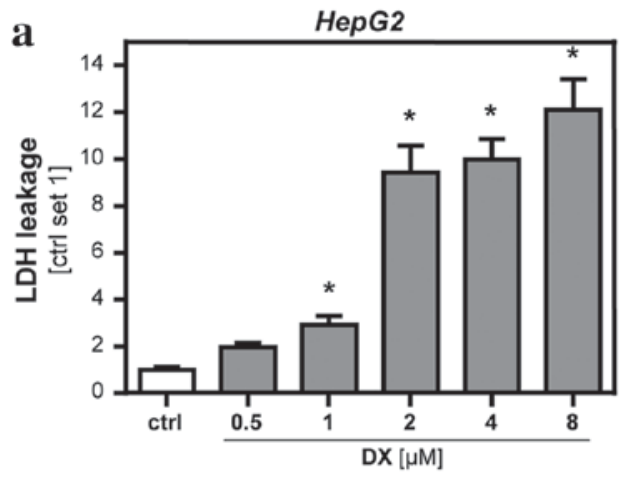

B a

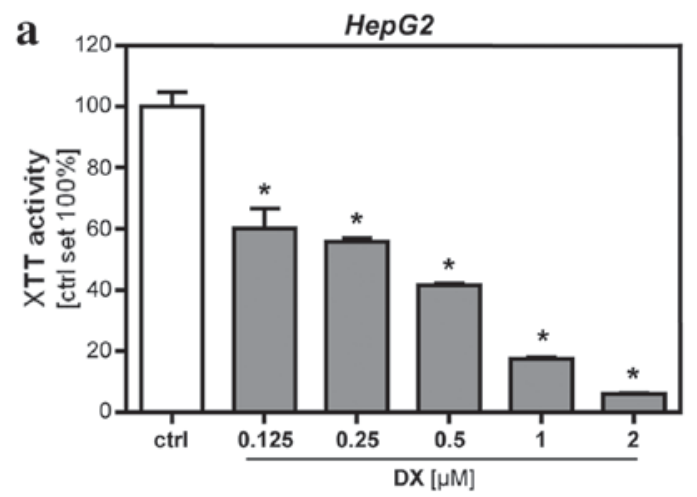

C a

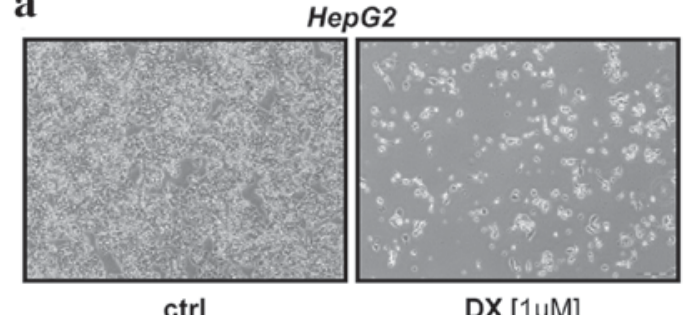

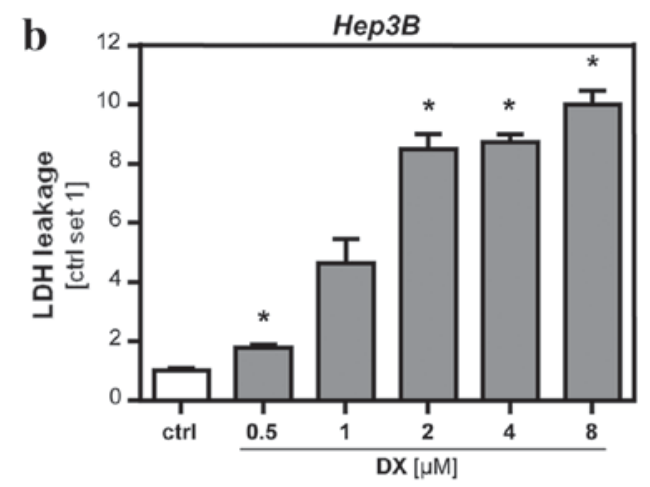

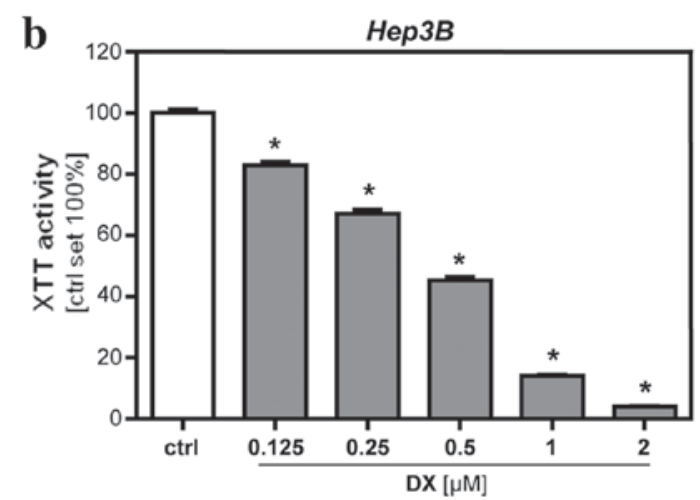

b

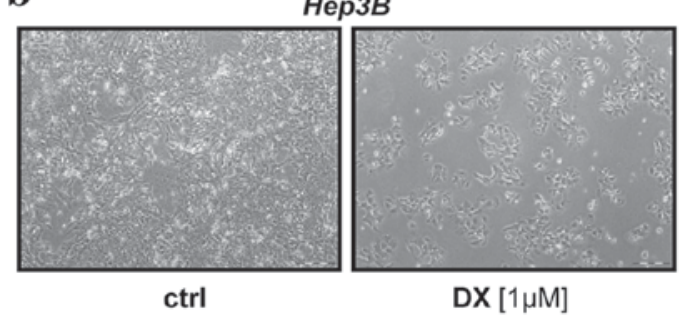

Figure 1. Selection of HCC cells surviving DX treatment. HepG2 and Hep3B human HCC cell lines were treated with the indicated concentrations of DX for 48 h. (A) Analysis of LDH leakage of (a) HepG2 and (b) Hep3B cells into the supernatant. DX caused a dose-dependent increase in LDH levels in the supernatants of the two cell lines. (B) Quantification of XTT activity as a measure of cell viability of (a) HepG2 and (b) Hep3B cells. DX treatment induced a dose-dependent decrease in XTT activity in the two cell lines. (C) Phase-contrast microscopy of ctrl cells and cells treated with $1 \mu$ M DX: (a) HepG2 and (b) Hep3B cells (magnification, 40x). In the two cell lines DX treatment caused a marked reduction of cell density, indicative of induced toxicity. ${ }^{*} \mathrm{P}<0.05$ vs. ctrl group. HCC, hepatocellular carcinoma; DX, doxorubicin; LDH, lactate dehydrogenase; ctrl, untreated control.

mesenchymal shape within the first 6 days after treatment with doxorubicin (Fig. 2A). By contrast, HepG2 ${ }^{\text {ctr }}$ and Hep3B ${ }^{\text {ctr }}$ did not change their characteristic, cubic and compact cell form during the whole observation period. Additionally, expression of the epithelial-mesenchymal transition (EMT) marker SNAIL was 1.9 -fold $(\mathrm{P}=0.03)$ increased in HepG $2^{\text {surv }}$ compared to HepG2 ${ }^{\text {ctr }}$ cells (Fig. 2B). Also in Hep3B ${ }^{\text {surv }}$ SNAIL expression was 5.2-fold $(\mathrm{P}=0.0002)$ higher compared with Hep3B ${ }^{\text {ctr }}$ cells (Fig. 2B). Functional analysis revealed similar rates of proliferation of $\mathrm{HCC}^{\text {surv }}$ and $\mathrm{HCC}^{\mathrm{ctr}}$ cells (data not shown). However, $\mathrm{HCC}^{\text {surv }}$ cells exhibited significantly increased migration in Boyden chamber assays compared to $\mathrm{HCC}^{\mathrm{ctr}}$ cells (Fig. 2C). Migration ability in HepG2 $2^{\text {surv }}$ was 2.4-fold increased $(\mathrm{P}=0.001)$ compared with HepG $2^{\text {ctr }}$. Hep3B 3 surv exhibited a 3.3 -fold increase $(\mathrm{P}=0.009)$ in migratory potential compared with Hep3B ${ }^{\text {ctr }}$.

Analysis of surviving HCC cells 3 weeks after doxorubicin treatment. After $\sim 1$ week, $\mathrm{HCC}^{\text {surv }}$ cells became confluent and required splitting. Subsequently, $\mathrm{HCC}^{\text {surv }}$ cells were further cultured in parallel with $\mathrm{HCC}^{\mathrm{ctr}}$ cells for another 2 weeks. During that time, the $\mathrm{HCC}^{\text {surv }}$ cells reverted to their original shape. The spindle-like, outstretched cell form disappeared and the HepG $2^{\text {surv }}$ and Hep3B ${ }^{\text {surv }}$ no longer differed from their respective control cells (Fig. 3A). SNAIL expression and migratory potential were similar in $\mathrm{HCC}^{\text {surv }}$ and $\mathrm{HCC}^{\mathrm{ctr}}$ cells (data not shown). However, 3 weeks following doxorubicin treatment, HCC $^{\text {surv }}$ cells exhibited significantly higher expression levels of MDR1 (ABCB1) and MRP1 (ABCC1) compared to $\mathrm{HCC}^{\mathrm{ctr}}$ cells (Fig. 3B). ABCB1 expression was 1.7-fold increased in HepG2 $2^{\text {surv }}(\mathrm{P}=0.029)$ and 3.4 -fold in Hep3B ${ }^{\text {surv }}(\mathrm{P}=0.002)$ compared with their respective control cells. ABCC1 expression was increased 2.1-fold in HepG2 $2^{\text {surv }}$ $(\mathrm{P}=0.016)$ and 1.4 -fold in Hep3B ${ }^{\text {surv }}(\mathrm{P}=0.09)$ cells compared with their respective control cells. Consistently, HCC $^{\text {surv }}$ cells tolerated significantly increased doxorubicin concentrations compared with HCC ${ }^{\text {ctr }}$ cells (Fig. 3C). Although XTT-activity was reduced to $33 \%$ in HepG $2^{\text {ctr }}$ treated with $0.5 \mu \mathrm{M}$ doxorubicin, HepG $2^{\text {surv }}$ exhibited an XTT-activity of $74 \%(\mathrm{P}=0.0001)$ upon incubation with the same doxorubicin dose. Similarly, 
A

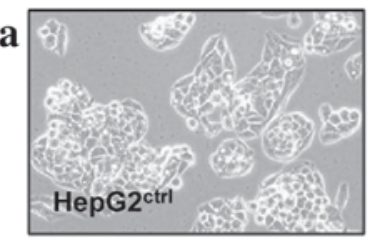

b
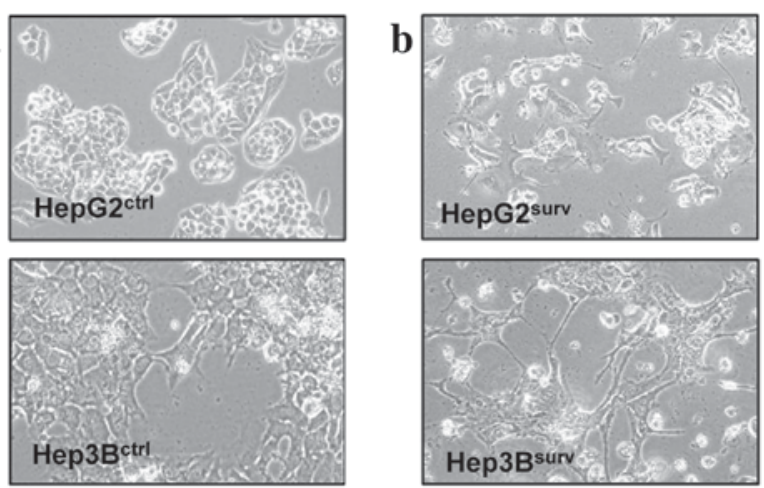

B
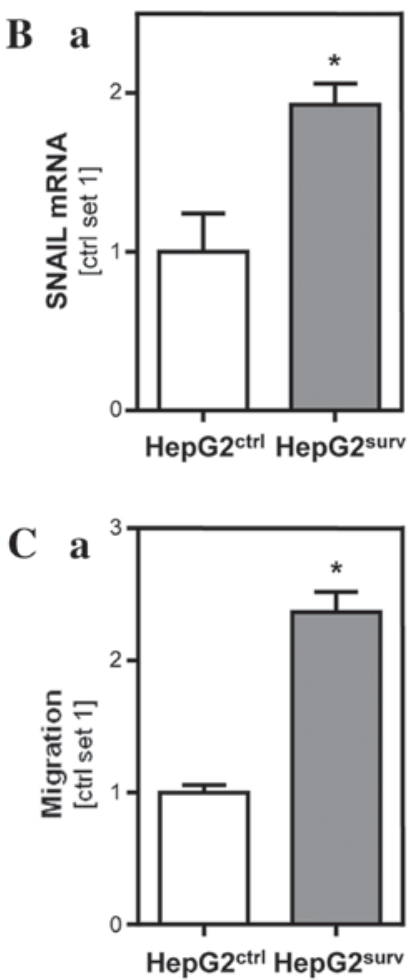
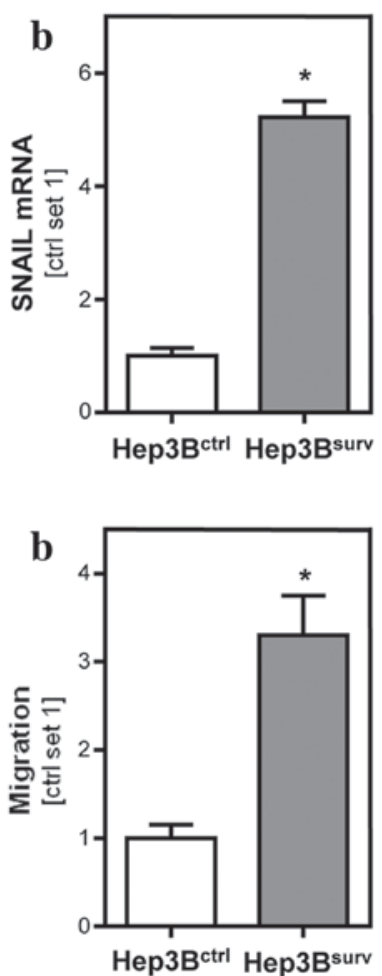

Figure 2. Analysis of surviving HepG2 and Hep3B HCC cells in the early phase subsequent to doxorubicin treatment. (A) Phase-contrast microscopy of (a) untreated control cells (HepG2 $2^{\text {ctrl }}$ and Hep3B $\left.{ }^{\text {ctrl }}\right)$ and (b) cells surviving 1 week after doxorubicin treatment $\left(\mathrm{HepG} 2^{\text {surv }}\right.$ and Hep3B $\mathrm{B}^{\text {surv }}$; magnification, 100x). The two $\mathrm{HCC}^{\text {surv }}$ cell lines exhibited spindle-like, outstretched cell forms, whereas HepG2 $2^{\text {surv }}$ cells retained cubic, compact forms. (B) Analysis of SNAIL mRNA levels by reverse transcription-quantitative polymerase chain reaction in (a) HepG2 and (b) Hep3B cells. HCC $^{\text {surv }}$ cells exhibited significantly higher SNAIL expression than $\mathrm{HCC}^{\mathrm{ctr}}$ cells. (C) Analysis of migratory potential by Boyden Chamber assays in (a) HepG2 and (b) Hep3B cells. HepG2 $2^{\text {surv }}$ cells exhibited significantly higher migratory activity than HepG2 ${ }^{\text {ctr }}$ cells. ${ }^{*} \mathrm{P}<0.05$ vs. ctrl group. ${ }^{\text {surv }}$, surviving cells; ${ }^{\text {ctrl }}$, untreated control.

impairment of XTT-activity in response to $0.5 \mu \mathrm{M}$ doxorubicin in Hep3B $\mathrm{B}^{\text {surv }}$ cells (64\%) was significantly lowered $(\mathrm{P}=0.0006)$ compared with the reduction of XTT-activity (34\%) in Hep3B ${ }^{\text {ctr }}$ cells.

\section{Discussion}

The aim of the present study was to analyze human HCC cells surviving doxorubicin treatment in vitro, in an experimental

setting resembling the circumstances of HCC cells surviving doxorubicin application during TACE. For this, two different human HCC cell lines were incubated with doxorubicin at a concentration that killed $>80 \%$ of the tumor cells within $48 \mathrm{~h}$. The applied concentration of doxorubicin was in the range of tissue drug concentrations found in experimental TACE models in vivo, as well as in HCC explants of patients after the administration of TACE $(33,34)$. After 2 days, cell culture of surviving HCC cells was continued without doxorubicin exposure to mimic the situation of a single doxorubicin dose application during TACE.

Applying these experimental conditions, the present study observed an increased expression of the EMT marker SNAIL and morphological changes to a mesenchymal cell shape in HCC cells surviving doxorubicin exposure. Additionally, doxorubicin-surviving HCC cells exhibited increased migratory activity. Expression of SNAIL has been found to positively correlate with poor clinical outcomes in different types of cancer, including HCC (35). Furthermore, several studies indicate that EMT is a crucial event in HCC progression, being associated with tumor cell invasion and metastasis (36). Accordingly, a previous study reported that the incidences of poorly differentiated histology and intrahepatic metastases are significantly increased in post-TACE HCC tissues compared with in HCC tissues of patients who have not undergone TACE treatment (37). Furthermore, Zen et al (38) found a combined hepato-cholangiocellular phenotype was more frequently detected in HCC tissues after TACE compared to untreated HCC. In the context of these previous studies and the present in vitro data, one may hypothesize that doxorubicin application during TACE promotes a more malignant phenotype in surviving HCC cells. Currently, the present study can only speculate why the alterations in cell morphology, SNAIL expression and migratory activity in doxorubicin-surviving HCC cells regressed with prolonged cell culture. It may indeed have been an intermediate effect, or trypsinization and splitting of the cells may have triggered this reversion.

However, for up to 3 weeks after a single doxorubicin application, surviving HCC cells were significantly less susceptible to retreatment with doxorubicin. As a potential explanation for this increased chemotherapy resistance, significantly increased expression levels of MDR1 (ABCB1) and MRP1 $(\mathrm{ABCC} 1)$ were found; these genes are known to contribute to multidrug resistance in $\mathrm{HCC}(12-15,17,18,20)$. MRP1, which is overexpressed in HCC (39), performs an important role in the intrinsic multidrug resistance of $\mathrm{HCC}$ and is also associated with an aggressive tumor phenotype and has been suggested to indicate a progenitor cell origin (18).

Hypoxia, which also occurs after TACE through ischemia, is known to induce EMT and to enhance migration and therapy resistance in HCC cells $(40,41)$. The findings of the present study suggest that the chemotherapeutic agent doxorubicin may also cause unfavorable alterations in surviving HCC cells. These findings are of importance for the understanding of HCC recurrence observed subsequent to TACE. Future studies are required to analyze whether maintaining doxorubicin levels for a prolonged period, such as with doxorubicin-eluting beads, or switching to other anticancer agents may omit certain pathological alterations found in the present in vitro model. 
A $\mathbf{a}$
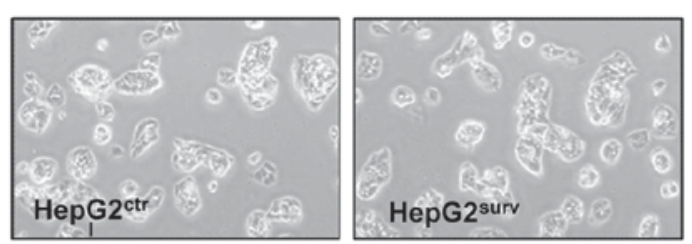

B
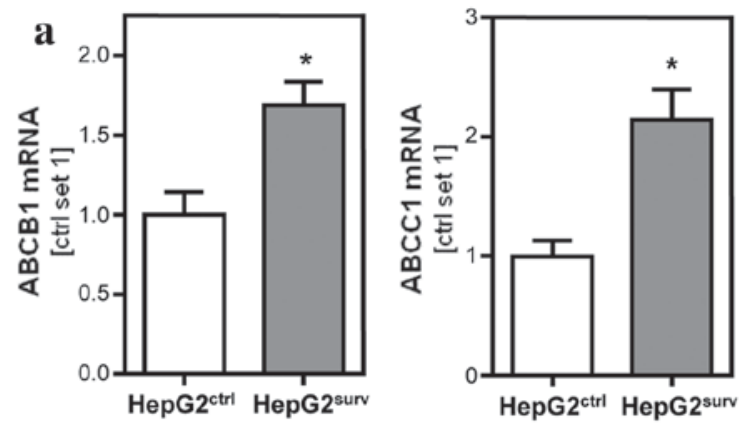

C

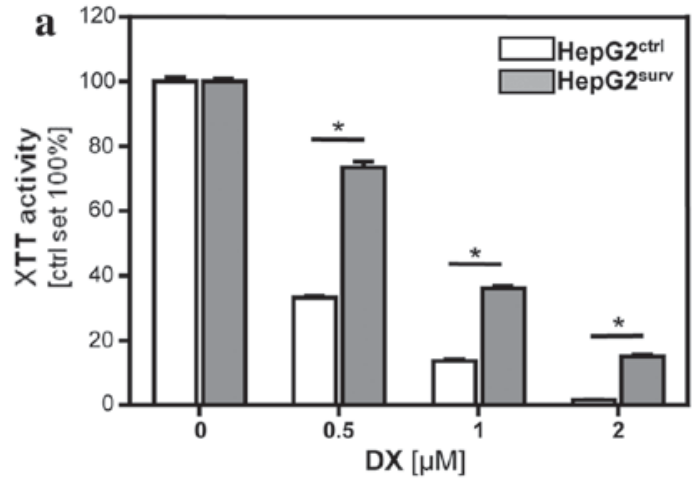

b
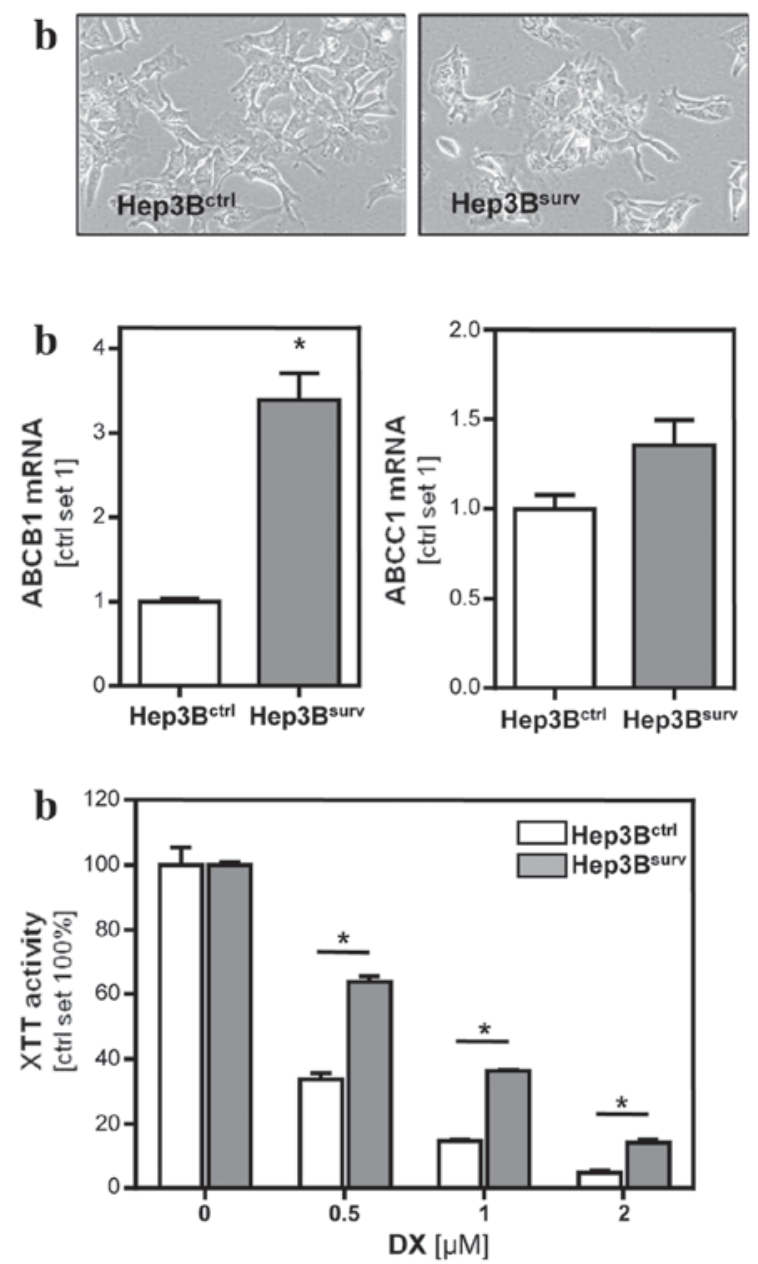

Figure 3. Analysis of surviving HCC cells 3 weeks after doxorubicin treatment. (A) Phase-contrast microscopy of untreated control cells [(a) HepG2 ${ }^{\text {ctrl }}$ and (b) Hep3B $\left.^{\text {ctrl }}\right]$ and cells surviving 3 weeks after DX treatment [(a) HepG2 $2^{\text {surv }}$ and (b) Hep3B ${ }^{\text {surv }}$ (magnification, 100x). The cell morphology of HCC ${ }^{\text {surv }}$ and HCC ${ }^{\text {ctrl }}$ cells did not significantly differ. (B) ABCB1 and ABCC1 mRNA expression analyzed by reverse transcription-quantitative polymerase chain reaction in (a) HepG2 and (b) Hep3B cells. ABCB1 expression was significantly higher in HCC $^{\text {surv }}$ compared with HCC ${ }^{\text {ctrl }}$ cells. In addition, ABCC1 expression levels were significantly higher in HepG2 ${ }^{\text {surv }}$ cells compared with HepG $2^{\text {ctr }}$ cells, whereas differences did not reach the level of significance in Hep3B ${ }^{\text {surv }}$ vs. Hep3B ${ }^{\text {ctrl }}$ cells (C) XTT activity of untreated control cells and DX-surviving cells following re-incubation with the indicated concentrations of DX for 48 h: (a) HepG2 and (b) Hep3B. $\mathrm{HCC}^{\text {surv }}$ cells revealed significantly higher XTT activity than $\mathrm{HCC}^{\mathrm{ctr}}$ cells in response to treatment with the same doxorubicin concentrations, as an indication that $\mathrm{HCC}^{\text {surv }}$ cells tolerated significantly higher doxorubicin concentrations compared with $\mathrm{HCC}{ }^{\text {ctr }}$ cells. ${ }^{*} \mathrm{P}<0.05$ vs. ctrl group. DX, doxorubicin; ${ }^{\text {surv }}$, surviving cells; ${ }^{\text {ctrl }}$, untreated control.

Furthermore, it must be investigated whether such altered therapeutic strategies may improve the outcome of HCC patients following TACE treatment, and this in vitro model may be used for preclinical analyses addressing these questions.

\section{Acknowledgements}

The authors would like to thank Mrs. Birgitta Ott-Rötzer (University Hospital Regensburg, Germany) for excellent technical assistance. This study was supported by grants from the German Research Association (grant nos. FOR2127 and KFO262) and an educational grant from the Medical Faculty of the University Hospital Regensburg.

\section{References}

1. Lin S, Hoffmann K and Schemmer P: Treatment of hepatocellular carcinoma: A systematic review. Liver Cancer 1: 144-158, 2012.

2. Mazzanti R, Arena U and Tassi R: Hepatocellular carcinoma: Where are we? World J Exp Med 6: 21-36, 2016.
3. Bruix J, Boix L, Sala M and Llovet JM: Focus on hepatocellular carcinoma. Cancer Cell 5: 215-219, 2004.

4. Hernandez-Gea V, Toffanin S, Friedman SL and Llovet JM: Role of the microenvironment in the pathogenesis and treatment of hepatocellular carcinoma. Gastroenterology 144: 512-527, 2013.

5. Belghiti J: Treatment of hepatocellular carcinoma. Bull Acad Natl Med 196: 97-103, 2012.

6. Biolato M, Marrone G, Racco S, Di Stasi C, Miele L, Gasbarrini G, Landolfi R and Grieco A: Transarterial chemoembolization (TACE) for unresectable HCC: A new life begins? Eur Rev Med Pharmacol Sci 14: 356-362, 2010.

7. Xiao EH, Guo D and Bian DJ: Effect of preoperative transcatheter arterial chemoembolization on angiogenesis of hepatocellular carcinoma cells. World J Gastroenterol 15: 4582-4586, 2009.

8. Park W, Chung YH, Kim JA, Jin YJ, Lee D, Shim JH, Lee D, Kim KM, Lim YS, Lee HC, et al: Recurrences of hepatocellular carcinoma following complete remission by transarterial chemoembolization or radiofrequency therapy: Focused on the recurrence patterns. Hepatol Res 43: 1304-1312, 2013.

9. Niessen C, Wiggermann P, Velandia C, Stroszczynski C and Pereira PL: Transarterial chemoembolization-status quo in Germany. Rofo 185: 1089-1094, 2013.

10. Thorn CF, Oshiro C, Marsh S, Hernandez-Boussard T, McLeod H, Klein TE and Altman RB: Doxorubicin pathways: Pharmacodynamics and adverse effects. Pharmacogenet Genomics 21: 440-436, 2011. 
11. Tacar O, Sriamornsak P and Dass CR: Doxorubicin: An update on anticancer molecular action, toxicity and novel drug delivery systems. J Pharm Pharmacol 65: 157-170, 2013.

12. Li G, Chen X, Wang Q, Xu Z, Zhang W and Ye L: The roles of four multi-drug resistance proteins in hepatocellular carcinoma multidrug resistance. J Huazhong Univ Sci Technolog Med Sci 27: 173-175, 2007.

13. Wang J, Chan JY, Fong CC, Tzang CH, Fung KP and Yang M: Transcriptional analysis of doxorubicin-induced cytotoxicity and resistance in human hepatocellular carcinoma cell lines. Liver Int 29: 1338-1347, 2009.

14. Pang E, Hu Y, Chan KY, Lai PB, Squire JA, Macgregor PF, Beheshti B, Albert M, Leung TW and Wong N: Karyotypic imbalances and differential gene expressions in the acquired doxorubicin resistance of hepatocellular carcinoma cells. Lab Invest 85: 664-674, 2005.

15. Ambudkar SV, Kimchi-Sarfaty C, Sauna ZE and Gottesman MM: P-glycoprotein: From genomics to mechanism. Oncogene 22: $7468-7485,2003$

16. Ye CG, Wu WK, Yeung JH, Li HT, Li ZJ, Wong CC, Ren SX, Zhang L, Fung KP and Cho CH: Indomethacin and SC236 enhance the cytotoxicity of doxorubicin in human hepatocellular carcinoma cells via inhibiting P-glycoprotein and MRP1 expression. Cancer Lett 304: 90-96, 2011.

17. Park JG, Lee SK, Hong IG, Kim HS, Lim KH, Choe KJ, Kim WH, Kim YI, Tsuruo T and Gottesman MM: MDR1 gene expression: Its effect on drug resistance to doxorubicin in human hepatocellular carcinoma cell lines. J Natl Cancer Inst 86: 700-705, 1994.

18. Vander Borght S, Komuta M, Libbrecht L, Katoonizadeh A, Aerts R, Dymarkowski S, Verslype C, Nevens F and Roskams T: Expression of multidrug resistance-associated protein 1 in hepatocellular carcinoma is associated with a more aggressive tumour phenotype and may reflect a progenitor cell origin. Liver Int 28 : 1370-1380, 2008.

19. Itsubo M,IshikawaT,Toda Gand Tanaka M:Immunohistochemical study of expression and cellular localization of the multidrug resistance gene product P-glycoprotein in primary liver carcinoma. Cancer 73: 298-303, 1994.

20. Chan JY, Chu AC and Fung KP: Inhibition of P-glycoprotein expression and reversal of drug resistance of human hepatoma HepG2 cells by multidrug resistance gene (mdr1) antisense RNA. Life Sci 67: 2117-2124, 2000.

21. Sun BT, Zheng LH, Bao YL, Yu CL, Wu Y, Meng XY and Li YX: Reversal effect of Dioscin on multidrug resistance in human hepatoma HepG2/adriamycin cells. Eur J Pharmacol 654: 129-134, 2011

22. Yang L, Liu X, Lu Z, Yuet-Wa Chan J, Zhou L, Fung KP, Wu P and $\mathrm{Wu} \mathrm{S}$ : Ursolic acid induces doxorubicin-resistant HepG2 cell death via the release of apoptosis-inducing factor. Cancer Lett 298: 128-138, 2010

23. Bosserhoff AK, Moser M, Schölmerich J, Buettner R and Hellerbrand C: Specific expression and regulation of the new melanoma inhibitory activity-related gene MIA2 in hepatocytes. J Biol Chem 278: 15225-311, 2003.

24. Hellerbrand C, Mühlbauer M, Wallner S, Schuierer M, Behrmann I, Bataille F, Weiss T, Schölmerich J and Bosserhoff AK: Promoter-hypermethylation is causing functional relevant downregulation of methylthioadenosine phosphorylase (MTAP) expression in hepatocellular carcinoma. Carcinogenesis 27: 64-72, 2006.

25. Dorn C, Weiss TS, Heilmann J and Hellerbrand C: Xanthohumol, a prenylated chalcone derived from hops, inhibits proliferation, migration and interleukin-8 expression of hepatocellular carcinoma cells. Int J Oncol 36: 435-441, 2010.
26. Livak KJ and Schmittgen TD: Analysis of relative gene expression data using real-time quantitative PCR and the 2(-Delta Delta C(T)) method. Methods 25: 402-408, 2001.

27. Al-Qubaisi M, Rozita R, Yeap SK, Omar AR, Ali AM and Alitheen NB: Selective cytotoxicity of goniothalamin against hepatoblastoma HepG2 cells. Molecules 16: 2944-2959, 2011.

28. Fan LL, Sun GP, Wei W, Wang ZG, Ge L, Fu WZ and Wang H: Melatonin and doxorubicin synergistically induce cell apoptosis in human hepatoma cell lines. World J Gastroenterol 16: 1473-1481, 2010.

29. Al-Abd AM, Mahmoud AM, El-Sherbiny GA, El-Moselhy MA, Nofal SM, El-Latif HA, El-Eraky WI and El-Shemy HA Resveratrol enhances the cytotoxic profile of docetaxel and doxorubicin in solid tumour cell lines in vitro. Cell Prolif 44: 591-601, 2011.

30. Hu QD, Chen W, Yan TL, Ma T, Chen CL, Liang C, Zhang Q, Xia XF, Liu H, Zhi X, et al: NSC 74859 enhances doxorubicin cytotoxicity via inhibition of epithelial-mesenchymal transition in hepatocellular carcinoma cells. Cancer Lett 325: 207-213, 2012.

31. Gambari R, Hau DK, Wong WY and Chui CH: Sensitization of Hep3B hepatoma cells to cisplatin and doxorubicin by corilagin. Phytother Res 28: 781-783, 2014.

32. Shiraga K, Sakaguchi K, Senoh T, Ohta T, Ogawa S, Sawayama T, Mouri H, Fujiwara A and Tsuji T: Modulation of doxorubicin sensitivity by cyclosporine A in hepatocellular carcinoma cells and their doxorubicin-resistant sublines. J Gastroenterol Hepatol 16: 460-466, 2001

33. Namur J, Wassef M, Millot JM, Lewis AL, Manfait M and Laurent A: Drug-eluting beads for liver embolization: Concentration of doxorubicin in tissue and in beads in a pig model. J Vasc Interv Radiol 21: 259-267, 2010.

34. Namur J, Citron SJ, Sellers MT, Dupuis MH, Wassef M, Manfait M and Laurent A: Embolization of hepatocellular carcinoma with drug-eluting beads: Doxorubicin tissue concentration and distribution in patient liver explants. J Hepatol 55: 1332-1338, 2011.

35. Peinado H, Olmeda D and Cano A: Snail, Zeb and bHLH factors in tumour progression: An alliance against the epithelial phenotype? Nat Rev Cancer 7: 415-428, 2007.

36. van Zijl F, Zulehner G, Petz M, Schneller D, Kornauth C, Hau M, Machat G, Grubinger M, Huber H and Mikulits W: Epithelial-mesenchymal transition in hepatocellular carcinoma. Future Oncol 5: 1169-1179, 2009.

37. Nishihara Y, Aishima S, Kuroda Y, Iguchi T, Taguchi K, Asayama Y, Taketomi A, Kinukawa N, Honda $\mathrm{H}$ and Tsuneyoshi M: Biliary phenotype of hepatocellular carcinoma after preoperative transcatheter arterial chemoembolization. J Gastroenterol Hepatol 23: 1860-1868, 2008.

38. Zen C, Zen Y, Mitry RR, Corbeil D, Karbanová J, O'Grady J, Karani J, Kane P, Heaton N, Portmann BC and Quaglia A: Mixed phenotype hepatocellular carcinoma after transarterial chemoembolization and liver transplantation. Liver Transpl 17: 943-954, 2011.

39. Hoffmann K, Shibo L, Xiao Z, Longerich T, Büchler MW and Schemmer P: Correlation of gene expression of ATP-binding cassette protein and tyrosine kinase signaling pathway in patients with hepatocellular carcinoma. Anticancer Res 31: 3883-3890, 2011.

40. Zhang L, Huang G, Li X, Zhang Y, Jiang Y, Shen J, Liu J, Wang Q Zhu J, Feng X, et al: Hypoxia induces epithelial-mesenchymal transition via activation of SNAI1 by hypoxia-inducible factor$1 \alpha$ in hepatocellular carcinoma. BMC Cancer 13: 108, 2013.

41. Luo D, Wang Z, Wu J, Jiang C and Wu J: The role of hypoxia inducible factor-1 in hepatocellular carcinoma. Biomed Res Int 2014: 409272, 2014. 